\title{
USE OF MATHEMATIC PROGRAM PACKAGES FOR IMPROVING AND MODERNIZING TEACHING MATHEMATICS IN THE FACULTY OF COMPUTER SCIENCE AND INFORMATION TECHNOLOGIES IN RIGA TECHNICAL UNIVERSITY
}

\author{
Inta Volodko, Sarmite Cernajeva \\ Riga Technical University, Latvia \\ inta.volodko@rtu.lv, sarmite.cernajeva@inbox.lv
}

\begin{abstract}
Questions about the quality improvement of the school system are topical at the moment. Universities must be prepared to offer the young person an education that prepares him/her to be competitive in these new work conditions, which is why the main goal of the university in this changing time is development of the of mental skills, cognitive research attitudes and IT skills. That is why mathematics study programmes and didactics must be improved, based on IT, creating more modern learning materials based on modern technologies and offering access to them via the Internet. During the period 2005 to 2014, students from the Faculty of Computer Science and Information Technologies, parallel to the regular teaching of mathematics, were taught a program package MATHEMATICA. In the last two years it was changed to a program package MATLAB. For two semesters the first course students have had laboratory work at computers, where students are acquiring the ability to solve tasks that are similar to those in their practical work with the help of a mathematical program. This year's first course students were questioned about MATLAB classes. 172 students took part in a survey, and the majority of them believe that MATLAB classes are useful and necessary for students and that they help them understand mathematical algorithms to solve tasks.
\end{abstract}

Keywords: creation of IT skills, program packages MATLAB, MATHCAD.

\section{Introduction}

Nowadays, along with the rising amount of technology, there is a demand for qualified specialists who are quickly able to orientate in the newest scientific achievements, modern technologies and materials, and are able to create a quality global business. That is why education system nowadays must be ready to offer a young person an education that makes him or her competitive in these new work conditions, and raises his/her level of competencies. That is why pedagogues of mathematics must work out a study program that is based on new technologies, which would give opportunities for students to find an application that will support their knowledge of mathematics during the study process.

Choosing the appropriate teaching methods is one of the most important competencies for any teaching staff. Nowadays, it is more and more necessary to actively involve pupils and students into the study process [1]. That is why the teaching staff must manage different teaching systems. The broader the range of teaching methods, the better they can be applied to different situations that appear during the study process. New methods and tendencies appear also in teaching mathematics. Usage of computers and mathematical programs is spreading more and more for mathematical calculations, as well as for modelling mechanic and economic processes. Knowledge and skills necessary for research and product workout also change: nowadays, knowledge of mathematical and computational algorithm for an ordinary engineer plays a greater and greater role [2].

Teaching mathematical programs parallel to a traditional course is being introduced all over the world, and MATLAB is the most popular program for that. MATLAB has been introduced into teaching mathematics in many countries in Europe: for example, [3] describes a successful introduction of MATLAB into the study process in two universities of Great Britain, [4] - using MATLAB in university of Denmark, [5] - a new course of mathematics in the Technical University of Sofia, in Bulgaria, which is based on MATLAB and MAPLE. MATLAB is also used in the study process in other parts of the world. The paper [6] describes how MATLAB is used in teaching mathematics for engineering science students in a university in Saudi Arabia. In the Cincinnati University, in the United States of America, MATLAB was integrated as a tool to help students understand engineer-technical conceptions, explore and analyse solutions for complicated problems, as well as, being used to effectively show results [7]. In another USA university - the University of Toledo - MATLAB is being used to help students solve business mathematics tasks easier and quicker [8]. Lecturers from the Australian University of Queensland [9] started using MATLAB at the beginning of the $21^{\text {st }}$ century as an instrument for numerical analyses and visualisation of the results. 
At first, Australian students did not properly appreciate the possibilities of MATLAB and resisted this upgrade. But, with time and program improvement and support, as well as more effort from the teaching staff, the students appreciated MATLAB as a positive help to mathematical calculations.

Latvia is no exception. In 2014, a staff survey in one of the largest companies in Latvia that operates with telecommunication and information technologies on the popularity of mathematical programs was carried out [10]. 115 employees aged between 20 and 40 took part in the survey. First of all they were asked the following questions: "Which of the mathematical programs do you know and use for mathematical calculations?". The unquestioned leader in response to this question was MATLAB, which gained $45 \%$ of the votes, in the second place is MATHCAD - 27\%, a little behind is MATHEMATICA - $19 \%$, and the least votes MAPLE - 9\%. To the question: "Where did you acquire this program?" $86 \%$ replied that they studied it at the university, $9 \%$ acquired individually, but $5 \%$ learnt it at work.

In all the largest universities in Latvia, where mathematics is taught, mathematical programs are used. Of course, several faculties and several subjects in the Riga Technical University use the mathematical program. The Faculty of Civil Engineering students are shown work with MATHCAD during mathematics lectures. The Faculty of Computer Science and Information Technology $1^{\text {st }}$ course students have laboratory work for two semesters at the computer, during which the students acquire the skills to work with MATLAB. The students further gain MATLAB knowledge in the $2^{\text {nd }}$ course subject Numerical methods.

\section{Materials and methods}

Working as pedagogues of mathematics in the Faculty of Civil Engineering and the Faculty of Computer Science and Information Technology, there is now a question about using learned mathematical knowledge in a professional context. Answers are being sought for the questions: what should be taught, and how it should be done to enable the use of new knowledge of mathematics in professional work. When organizing practical classes, the students' level of knowledge, their intellectual abilities and cognitive benefits must be taken into consideration. The share of direct classes and individual work time must be considered according to the difficulty level of the topic and its significance to other study disciplines connected with mathematics.

Since the 1980s, integrated systems of automation of the mathematical calculations MATHCAD have gained wide popularity. It has been developed by the company Mathcad Soft (USA). Within this system, calculations are made with accustomed mathematical formulas and symbols.

The popularity of the program is confirmed by the fact that during the last few years several versions of this program have appeared. The program works in Windows software and is quite simple to use, because the form of mathematical expressions conforms with the one used by humans. Tasks can be solved both in a numerical way, and with special symbols. Data and results can be visualized in graphics. Students of Faculty of Civil Engineering are shown during lectures how to do the mentioned actions in MATHCAD,

For students from the RTU Faculty of Computer Science and Information Technology (abbreviation FCSIT) starting from academic year 2005/06, parallel to traditional teaching of mathematics, the usage of mathematical programs is being taught. During the period of the academic years 2005/06 to 2013/14, the FCSIT students were taught the MATHEMATICA program. Three years ago a change to MATLAB program set occurred. For 2 semesters the $1^{\text {st }}$ course students have held laboratory work at the computer, during which they acquire the ability to solve tasks, similar to those calculated during the practical works in the classroom, using mathematical programs. During laboratory work, with the help of MATHEMATICA or MATLAB, students learn to:

- define functions and calculate their values with the required precision;

- conduct operations with matrices and vectors;

- draw lines on a plane that are given in Cartesian coordinates, polar coordinates or parametric;

- draw lines and surfaces in space;

- solve algebraic equations or equations systems;

- calculate function limits and use to determination of asymptotes;

- find derivatives and apply them to the function analysis; 
- calculate indefinite, definite, improper and multiple integrals, and apply them to solving practical tasks;

- solve differential equations;

- find the power series expansion for given function and determine interval of the convergence.

As experience shows, students acquire mathematical programs with interest. Work with these programs helps students understand the algorithm of the task. A lot of students who have low grades in mathematics and who cannot solve the tasks themselves on paper can quite easily deal with this task in MATLAB, MATHEMATICA or MATHCAD software. In addition, when using mathematical programs, students can solve laborious tasks in a short time, solving which would take a lot of time and effort, if done on paper.

Using IT possibilities in teaching mathematics eases pedagogues work and also makes the learning process more interesting and effective. It also significantly improves the quality of education and the level of readiness in the labour market.

\section{Results and discussion}

To check how well students are able to apply MATLAB for solving mathematical tasks, 4 tests have to be taken in both semesters. Each test consists of $2-3$ tasks, which have to be solved with MATLAB. Students can use their notes, study books, materials on the Internet and other supporting materials during the tests. Each test is evaluated with 6 marks. The test is successfully passed if the student has correctly done at least $2 / 3$ of the tasks and has got at least 4 marks. Successful passing of all the tests is an obligatory requirement for all FCSIT $1^{\text {st }}$ year students. If any of the tests are not passed, the student is not allowed to take an exam.

How students succeed with passing the $1^{\text {st }}$ semester tests is shown in Figure 1. The test results of six groups of $1^{\text {st }}$ year FCSIT students were analysed; in total, 157 students. Figure 1 shows division of students in percentage after the first results of the tests: the first bar shows how many percent of students pass the test with the first attempt, the second - how many fail. As it is seen from the picture, the hardest one is the $1^{\text {st }}$ test; more than one third of the students cannot pass it with the first attempt. The greatest difficulties are with naming the function correctly. The most common mistakes are:

- students do not understand what the function argument is and do not put it in brackets, or put it incorrectly;

- put brackets incorrectly, thus, changing the order of the operation;

- incorrectly write the name of built-in function;

- do not know how to correctly convert the root of the fractional degrees, as well as, incorrectly record the power.

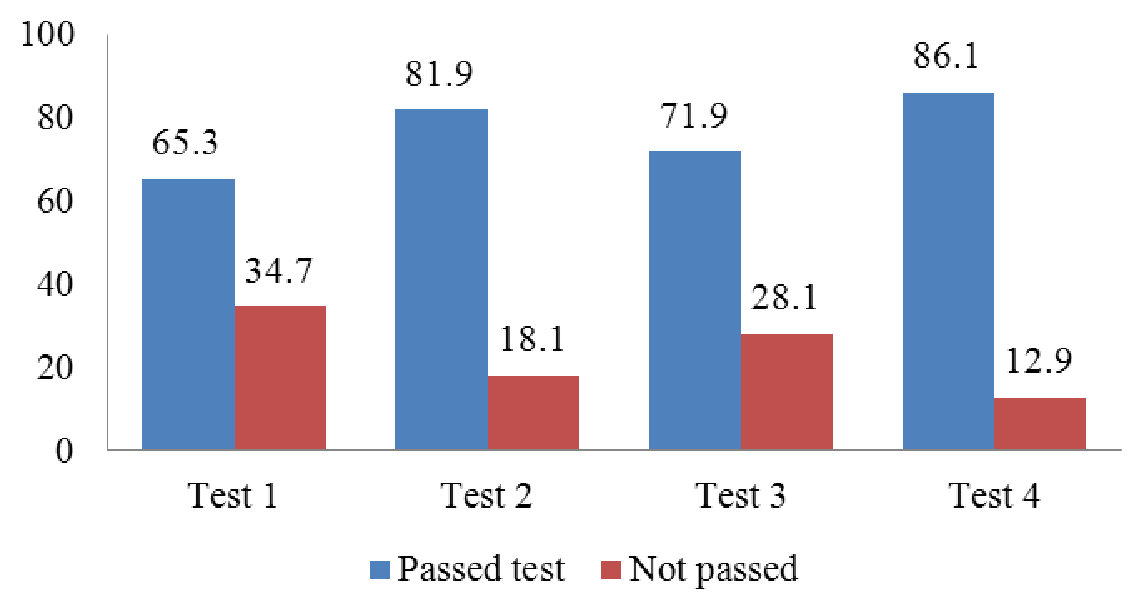

Fig. 1. Results of passing the $1^{\text {st }}$ semester tests

The results of the $2^{\text {nd }}$ test are much better, because the $2^{\text {nd }}$ test is about matrices and vectors, and with matrices and vectors you have to work with numbers, not functions. By the end of the semester, the results improve a lot, because students learn to work with MATLAB and do it with pleasure. In the 
$2^{\text {nd }}$ semester the results are even better, and only few students cannot pass the tests with the first attempt.

To find out the opinion of students about MATLAB teaching and using, the FCSIT $1^{\text {st }}$ course students were given a survey. 172 students took part in the survey. Answers to the $1^{\text {st }}$ question "Have you used program package MATLAB or other mathematical program (if yes, which one) before studies in the FCSIT?" are seen in Figure 2. It appeared that 26 of the correspondent students, or $15 \%$, were familiar to MATLAB already before the beginning of the studies. 14 students had used other programs. Between the most mentioned ones was WolframAlpha, some had mentioned MATHEMATICA and MATHCAD. But the majority of the students, 132 students, have not used mathematical programs before.

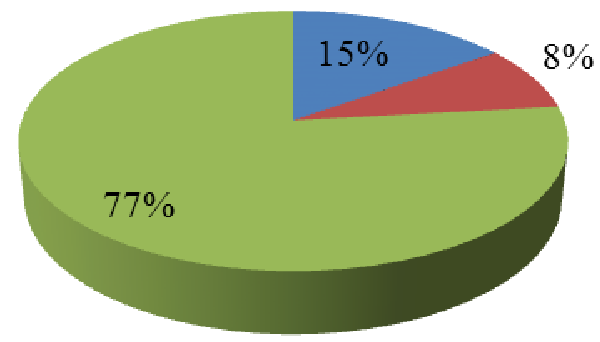

\author{
myes, I am familiar to \\ MATLAB already \\ before the beginning \\ of the studies \\ I had used other \\ program \\ no
}

Fig. 2. Amount of students (percentage) who used mathematical programs already before the studies

As the second was the question: "Do you think that acquisition of MATLAB is useful, should be taught to students?". The answers were the following (Fig.3): 141 students or $82 \%$ of the respondents believe that MATLAB should be taught to students, while, left $18 \%$ or 31 students, that it is not necessary. Of the main given reasons why they should not acquire MATLAB two were mentioned: 1) it is a program that costs money and is not available and cannot be used for free; 2) students do not see where it can be used.

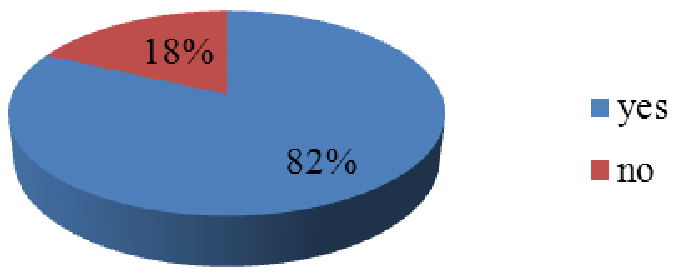

Fig 3. Amount of answers (percentage) to the question if MATLAB should be taught

Unfortunately, only a bit over one third of the students (61 student or $35 \%$ ) use MATLAB outside laboratory works (Fig. 4).

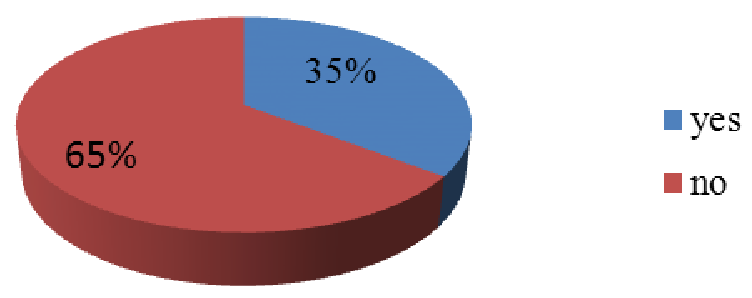

Fig. 4. Amount of students (percentage) who use MATLAB outside laboratory works 
Figure 5 shows what students use MATLAB outside classes for. Most of these, 61 students (76\%), use MATLAB for doing homework and checking results of completed homework. Some students $(11 \%)$ use MATLAB to prepare for tests and exams, the same amount use it as an instrument for numerical calculations not only in mathematics, but also in other subjects, for example, electrotechnics and physics. One of the students mentioned that they use MATLAB at work.

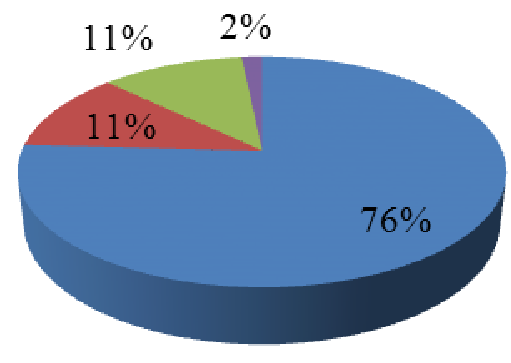

$$
\begin{aligned}
& \text { doing homework } \\
& \text { - preparing for tests } \\
& \text { and exam } \\
& \text { for numerical } \\
& \text { calculations } \\
& \text { at work }
\end{aligned}
$$

Fig. 5. Classes where students use MATLAB

The greatest part of the students $(64 \%)$ think that work with MATLAB helps them understand the algorithms of problem solving, while the rest $36 \%$ disagree (Fig. 6.).

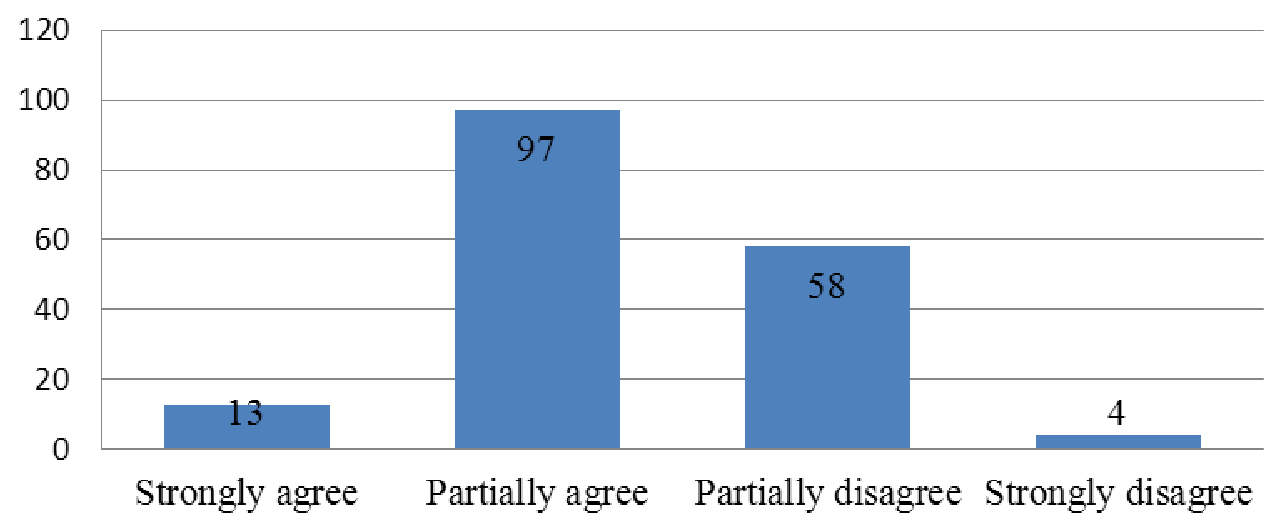

Fig. 6. Amount of answers on if MATLAB helps the understanding of algorithms of problem solving

The last question asked was "Would you like to acquire also other mathematical programs?". Figure 7 shows the answers to this question. Only 63 of the students or $37 \%$ would like to acquire other mathematical programs. MATHCAD was mentioned most often - 22 times, 10 times MATHEMATICA was mentioned, 9 times -MAPLE. Some students wrote that they have not heard about any of the programs, but would like to acquire all of them; some more - that would like to acquire some of the free programs. The majority of the 109 students who answered said that they would not like to acquire any more programs, with the given reason being the existing workloads and a lack of time.

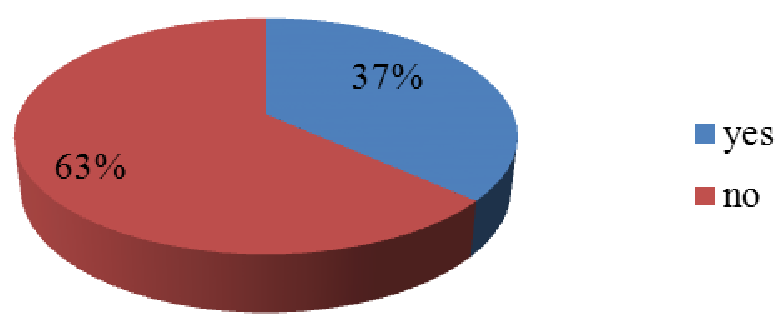

Fig. 7. Amount of students (percentage) who would like to acquire also other mathematical programs 
According to the results of the questionnaire it can be seen that the majority of the students appreciate the opportunities of MATLAB and are positive to its acquisition.

\section{Conclusions}

1. Using the IT possibilities in teaching mathematics eases the pedagogues' work, and also makes the learning process more interesting and effective. It also significantly improves the quality of education and the level of preparedness in the labour market.

2. Work with mathematical programs helps students understand the algorithm of the task. In addition, students can solve laborious tasks in a short time, which would take a lot of time and effort, if done on paper.

3. However, despite the fact that a computer helps homework, using it throughout the mathematics course does not have such a positive effect, because, a computer program gives a ready answer to a task, but does not show the pace of the solution. If studying only with a computer, a student will not be able to do all the tasks on the paper.

\section{References}

1. Bobalova M. Modern teaching methods in mathematics. Proceedings of the 26th International Business Information Management Association Conference, November 11-12, 2015, Madrid, Spain, pp. 539-545.

2. Richter Th., Rudlof S., Boehringer D., Grube P., Gruninger Gh., Helmig R., Rohde Gh., Bernlohr H., Munz C.D., Stock A. ViPLab - A virtual programming laboratory for mathematics and engineering. Proceedings of the 40th SEFI Annual Conference, September 23-26, 2012, Thessaloniki, Greece.

3. Nyamapfene A., Lynch S. Systematic integration of MATLAB into undergraduate mathematics teaching: Preliminary lessons from two UK institutions. Proceedings of IEEE Global Engineering Education Conference, April 10-13, 2016, Abu Dhabi, United Arab Emirates, pp. 1145-1148.

4. Karamehmedovic M. Mathematical beauty in service of deep approach to learning. Proceedings of the 43rd SEFI Annual Conference, June 29 - July 2, 2015, Orleans, France.

5. Konstantinov M., Pasheva V. Mathematical education in the Bulgarian technical universities. Proceedings of the 37th International Conference on Applications of Mathematics in Engineering and Economics, June 8-13, 2011, Sozopol, Bulgaria, pp. 375-388.

6. Abdul Majid M., Huneiti Z.A., Al-Naafa M.A., Balachandran W. A study of the effects of using MATLAB as a pedagogical tool for engineering mathematics. International Journal of Online Engineering, vol. 9, issue 2, 2013, pp. 27-35.

7. Heeg J.J., Flenar K., Ross J.A., Okel T., Deshpande T.A., Bucks G., Ossman K.A. Effective educational methods for teaching assistants in a first-year engineering MATLAB course. Proceedings of the 121st ASEE Annual Conference and Exposition, June 15-18, 2014, Indianapolis, United States.

8. Narayanan G. Teaching of essential matlab commands in applied mathematics course for engineering technology. Proceedings of the 114th Annual ASEE Conference and Exposition, June 24-27, 2007, Honolulu, United States.

9. Tonkes E.J., Loch B.I., Stace A.W. An innovative learning model for computation in first year mathematics. International Journal of Mathematical Education in Science and Technology, vol. 36, issue 7, 2005, pp. 751-759.

10. Roscina I., Volodko I. Использование систем компьютерной математики в Латвии и в Рижском Техническом университете. (Using of Computer Algebra Systems in Latvia and Riga Technical University). Proceedings of the international scientific conference "Education, science and economics in universities and schools. Integration to international educational space": Труды международной научной конференции „Образование, наука и экономика в вузах и школах. Интеграция в международное образовательное пространство”. March 24-29, 2014, Tsaghkadzor, Armenia, pp. 511-514. (In Russian). 